\title{
Descrição de uma espécie nova de Hentziectypus e da fêmea de $\boldsymbol{H}$. rafaeli (Araneae, Theridiidae)
}

\author{
Erica Helena Buckup ${ }^{1}$, Maria Aparecida L. Marques ${ }^{1}$ \& Everton Nei Lopes Rodrigues ${ }^{2}$
}

\footnotetext{
1. Museu de Ciências Naturais, Fundação Zoobotânica do Rio Grande do Sul, Rua Dr. Salvador França, 1427, 90690-000, Porto Alegre, RS, Brasil. (erica-buckup@fzzb.rs.gov.br aria-marques@fzb.rs.gov.br)

2. Laboratório Especial de Coleções Zoológicas, Instituto Butantan, Av. Vital Brazil, 1500, 05503-900, São Paulo, SP, Brasil. (enlrodrigues@yahoo.com.br)
}

\begin{abstract}
Description of a new species of Hentziectypus and the female of $\boldsymbol{H}$. rafaeli (Araneae, Theridiidae). Hentziectypus tayrona sp. nov. is described based on a male from Santa Marta, Colombia. The female of H. rafaeli Buckup \& Marques, 1991, is described for the first time and the distribution range is extended to Bolivia and South of Brazil.
\end{abstract}

KEYWORDS. Taxonomy, Neotropical, spiders, Colombia, Brazil.

RESUMO. Hentziectypus tayrona sp. nov. é descrita com base em um macho de Santa Marta, Colômbia. A fêmea de $H$. rafaeli Buckup \& Marques, 1991, é descrita pela primeira vez e a distribuição é estendida a Bolívia e ao sul do Brasil.

PALAVRAS-CHAVE. Taxonomia, Neotropical, aranhas, Colômbia, Brasil.

O gênero Hentziectypus, proposto por ARCHER (1946) com a espécie-tipo Theridion globosum Hentz, 1850, inclui atualmente 11 espécies, distribuídas principalmente nos Estados Unidos e na América Central (Platnick, 2012). Dessas, oito espécies são conhecidas por ambos os sexos. Levi (1955) colocou esse gênero na sinonímia de Achaearanea Strand, 1929. A única espécie do Brasil, A. rafaeli, foi descrita por Buckup \& MARQues (1991) sobre um macho colecionado na Ilha de Maracá, estado de Roraima. Yoshida (2008) restabeleceu Hentziectypus, caracterizado pelo palpo do macho com apófise média fusionada ao tégulo e alocada no capuz cimbial, próximo à base da projeção apical do címbio; êmbolo e condutor curtos; epígino com duas aberturas anteriores ao lobo posterior e ductos internos curtos. Yoshida (2008), em sua revisão, incluiu A. rafaeli em Cryptachaea; posteriormente BucKup et al. (2010) transferiram esta espécie para Hentziectypus pelas características do palpo do macho.

O objetivo é descrever uma espécie nova de Hentziectypus da Colômbia, apresentar a fêmea de $H$. rafaeli e ampliar a distribuição desta espécie até o sul do Brasil.

\section{MATERIAL E MÉTODOS}

Nomenclatura dos escleritos do palpo do macho segue Levi (1955) e Agnarsson et al. (2007). Abreviaturas utilizadas no texto: OLA, olhos laterais anteriores; OLP, olhos laterais posteriores; OMA, olhos médios anteriores; OMP, olhos médios posteriores. Todas as medidas estão expressas em milímetros.

A genitália da fêmea foi examinada e clarificada com óleo de cravo em temperatura ambiente, por aproximadamente uma hora, até a visualização das estruturas internas. As ilustrações foram realizadas em estereomicroscópio com câmara-clara acoplada.

Espécimes examinados pertencem às seguintes instituições (curadores entre parênteses): $\mathrm{MCN}$, Museu de Ciências Naturais, Fundação Zoobotânica do Rio Grande do Sul, Porto Alegre, Brasil (E. H. Buckup); MPEG, Museu Paraense Emílio Goeldi, Belém, Brasil (A. B. Bonaldo); SMNK, Staatliches Museum für Naturkunde, Karlsruhe, Alemanha (H. Höfer).

\section{Hentziectypus tayrona sp. nov.}

(Fig. 1)

Tipo. Holótipo macho, Parque Nacional Natural Tayrona, Santa Marta, Departamento de Magdalena, Colômbia, 1976/77, C. Kugler col., depositado no SMNK 359.

Etimologia. O substantivo em aposição refere-se à localidade-tipo.

Diagnose. O palpo do macho de Hentziectypus tayrona (Fig. 1) é similar ao de $H$. conjunctus (Gertsch \& Mulaik, 1936) pelo tégulo com ductos largos (vide LEVI, 1955, figs 16, 17); separa-se desta espécie pelo ápice do címbio truncado e êmbolo mais longo, aproximadamente duas vezes o comprimento do de $H$. conjunctus.

Macho (holótipo). Carapaça amarela, levemente pigmentada de cinza. Olhos anelados de vermelho. Quelíceras, lábio, enditos e esterno amarelo-claros. Pernas amarelas, com a região distal das tíbias e metatarsos manchada de cinza; tarsos com banda transversal mediana cinza. Abdômen oval, amarelado, mais longo do que alto, com margem anterior estridulada; dorso com pigmentação cinza em faixa transversal mediana que se estende até o ventre e com escasso pigmento branco na metade anterior; região posterior, com duas linhas de pigmento branco em "V" invertido. Ventre cinza-escuro, exceto em alguns pontos despigmentados.

Olhos médios anteriores maiores do que os demais; OMA afastados um do outro por dois terços de seu diâmetro e dos OLA pelo raio dos OMP. Olhos 
médios posteriores separados entre si pelo seu diâmetro e pelo seu raio dos OLP.

Medidas. Comprimento total 1,35. Carapaça: comprimento 0,62 , largura 0,52. Pernas, fórmula 1423 , comprimento I/II/III/IV: fềmures $0,82 / 0,57 / 0,42 / 0,60$; patelas + tíbias 0,72/0,52/0,45/0,62; metatarsos 0,52/0,32/0,27/0,35; tarsos 0,35/0,30/0,25/0,27. Comprimento total das pernas: 2,41/1,71/1,39/1,84.

Distribuição. Conhecida apenas da localidadetipo em Santa Marta, Colômbia.

\section{Hentziectypus rafaeli (Buckup \& Marques, 1991)}

(Figs 2, 3)

Achaearanea rafaeli Buckup \& MARques, 1991:86, figs 15, 16. Holótipo macho, Ilha de Maracá, Roraima, Brasil, 21-30.XI.1987, J. A. Rafael e equipe col., depositado no MCN 19325. Cryptachaea rafaeli; YoshidA, 2008:39.

Hentziectypus rafaeli; Buckup et al., 2010:351; Platnick, 2012.

Diagnose. Fêmea de Hentziectypus rafaeli separa-se de todas as espécies do gênero pelo epígino com aberturas esclerotinizadas, separadas entre si e demarcadas pela borda semicircular sobre o lobo posterior (Figs 2, 3).

Descrição fêmea (MPEG 11879). Carapaça e apêndices amarelo-claros, abdômen cinza-amarelado com pigmento castanho-claro ao redor das fiandeiras. Olhos médios anteriores maiores do que os demais; OMA distantes um do outro aproximadamente pelo seu raio e por quase um quarto do seu diâmetro dos OLA. Olhos médios posteriores afastados entre si por três quartos do seu diâmetro e por dois terços do seu diâmetro dos OLP.

Medidas. Comprimento total 2,28. Carapaça: comprimento 0,90, largura 0,75. Pernas, fórmula 1423, comprimento I/II/III/IV: fềmures 1,30/0,95/0,65/1,05; patelas + tíbias 1,18/0,88/0,68/1,02; metatarsos 1,05/0,65/0,42/0,68; tarsos $0,48 / 0,40 / 0,32 / 0,42$. Comprimento total das pernas: 4,01/2,88/2,07/3,17.

Variação. Comprimento total dos machos $(n=5)$ 1,38-1,95, carapaça 0,65-0,88, fêmur I 0,80-1,15. Fêmeas $(n=5)$ 2,10-2,28, carapaça 0,88-0,90, fêmur I 1,20-1,32. A coloração do corpo varia de amareloclaro a amarelo-escuro. A carapaça pode ter área cinza atrás dos olhos médios anteriores. $\mathrm{O}$ dorso do abdômen pode se apresentar salpicado de marrom e o ventre com maior quantidade deste pigmento. Alguns machos não apresentam o compacto grupo de longas cerdas ventrais no fêmur I (vide Buckup \& MARques, 1991, fig.16).

Nota. Machos e fêmeas foram colecionados juntos em Coari, Amazonas e apresentam o mesmo padrão de coloração.

Distribuição. Brasil (Roraima, Amazonas, Pará, Rio Grande do Sul) e Bolívia (Beni).

Material examinado. BRASIL, Amazonas: Coari (rio Urucu, Porto Urucu, Base de Operações Geólogo Pedro de Moura), đૈ, , 9, IX.2006, D. F. Candiani col. (MCN 45307, 45308) e $\precsim 2,2$ q (MPEG 11879, 11886, 12142); 2 9, IX.2006, S. C. Dias col. (MPEG 12176, 12649); , XI.2006, S. C. Dias col. (MCN 45306); Pará: Novo Progresso (Serra do Cachimbo), ô, 18.IX.2003, A. B. Bonaldo col. (MCN 38213); Rio Grande do Sul: Derrubadas (Parque Estadual do Turvo), ô, 27-31.X.2003, R. Ott et al. col. (MCN 23876). BOLÍVIA, Beni: (Estação Ecológica de Beni), วิ, 27-29. VII.1993, A. D. Brescovit col. (MCN 23876).
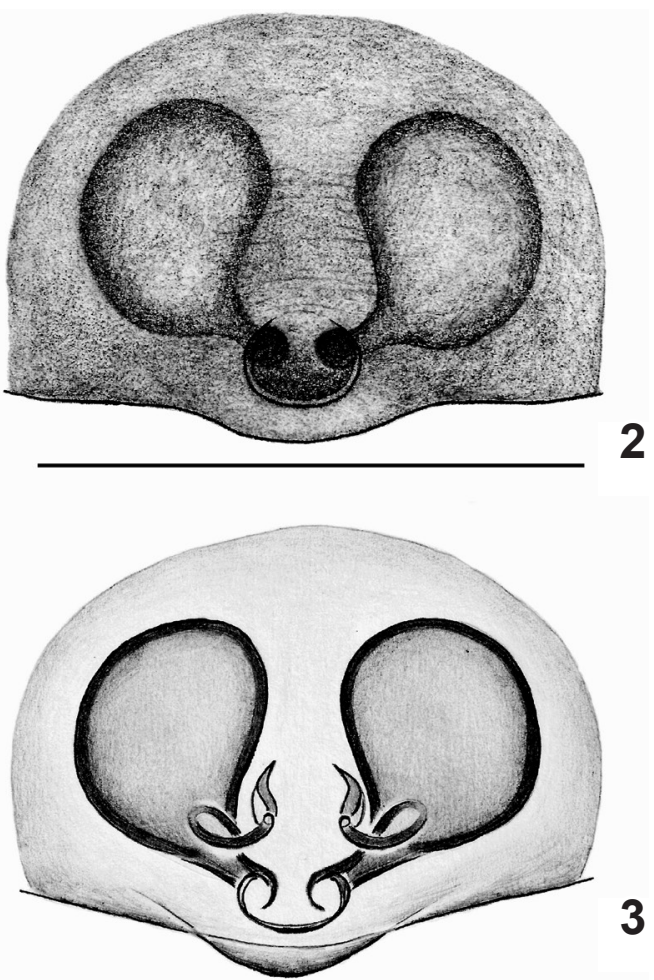

Figs 1-3. Hentziectypus tayrona sp. nov.: 1, palpo do macho, ventral. 2, 3. Hentziectypus rafaeli Buckup \& Marques, 1991, epígino: 2, ventral, 3 , dorsal, clarificado. Barras: Fig. 1, 0,1 mm; Figs 2, 3, 0,25 mm. 
Agradecimentos. Aos curadores do MPEG e SMNK pelo empréstimo de material. Aos consultores anônimos pelas sugestões. A FAPESP pela bolsa de Pós-Doutorado concedida a E. N. L. Rodrigues (processo 2011/02036-7).

\section{REFERÊNCIAS BIBLIOGRÁFICAS}

Agnarsson, I.; Coddington, J. A. \& Knoflach, B. 2007. Morphology and evolution of cobweb spider male genitalia (Araneae, Theridiidae). The Journal of Arachnology 35:334-395.

ARChER, A. F. 1946. The Theridiidae or comb-footed spiders of Alabama. Paper Alabama Museum of Natural History (22):1-67.
BucKup, E. H. \& Marques, M. A. L. 1991. Aranhas Theridiidae da Ilha de Maracá, Roraima, Brazil. II. Gênero Achaearanea (Araneae). Iheringia, Série Zoologia (71):81-89.

Buckup, E. H.; Maroues, M. A. L. \& Rodrigues, E. N. L. 2010. Três espécies novas de Cryptachaea e notas taxonômicas em Theridiidae (Araneae). Iheringia, Série Zoologia 100(4):341-355.

Levi, H. W. 1955. The spider genera Coressa and Achaearanea in America north of México. American Museum Novitates 1718:1-33.

PlATNICK, N. I. 2012. The world spider catalog, version 12.5. American Museum of Natural History. Disponível em: $<$ http://research.amnh. org/iz/spiders/catalog $>$. Acesso em 15.03.2012.

YoshidA, H. 2008. A revision of the genus Achaearanea (Araneae: Theridiidae). Acta Arachnologica 57(1):37-40. 